\title{
Characterization of local invariances in the ascending ferret auditory system
}

\author{
Jean F Lienard ${ }^{1 *}$, Stephen V David ${ }^{2}$, Alexander G Dimitrov ${ }^{1}$ \\ From The Twenty Third Annual Computational Neuroscience Meeting: CNS*2014 \\ Québec City, Canada. 26-31 July 2014
}

Local probabilistic invariances, defined by the range of physical transformations that can be applied to a sensory stimulus without changing the corresponding neural response [1], are largely unstudied in auditory cortex. We propose to assess these invariances using existing and new experimental neurophysiological data recorded from multiple stages of the ferret auditory processing hierarchy.

We hypothesize that neurons in the auditory pathway will show increasing degrees of local invariance at successively more central stages of the processing hierarchy. To test this hypothesis, we analyzed spiking activity recorded from single neurons in the primary auditory cortex (A1) and in the secondary auditory cortex (PEG) of awake, passively listening animals during presentation of two types of stimuli commonly known to evoke activity in the auditory system. The first set of stimuli was a sequence of isolated pure tones with randomly varying frequency, spanning 5-6 octaves and encompassing the best frequencies of the recorded neurons. The second was a sequence of bandpass noise bursts with varied durations, consisting of 20-30 bursts that logarithmically tile 5-7 octaves, thus achieving a bandwidth each of approximately 0.25 octave. Using these data, we have analyzed local invariance to frequency shifts by estimating the width of the tuning curve for the best responding neurons, and found that the corresponding 95\% confidence interval was significantly larger in PEG than in A1 (Figure 1). We have also characterized local invariance to time shifts with the recordings obtained in response to bandpass noise by modeling the temporal jitter of individual neurons as independent processes as
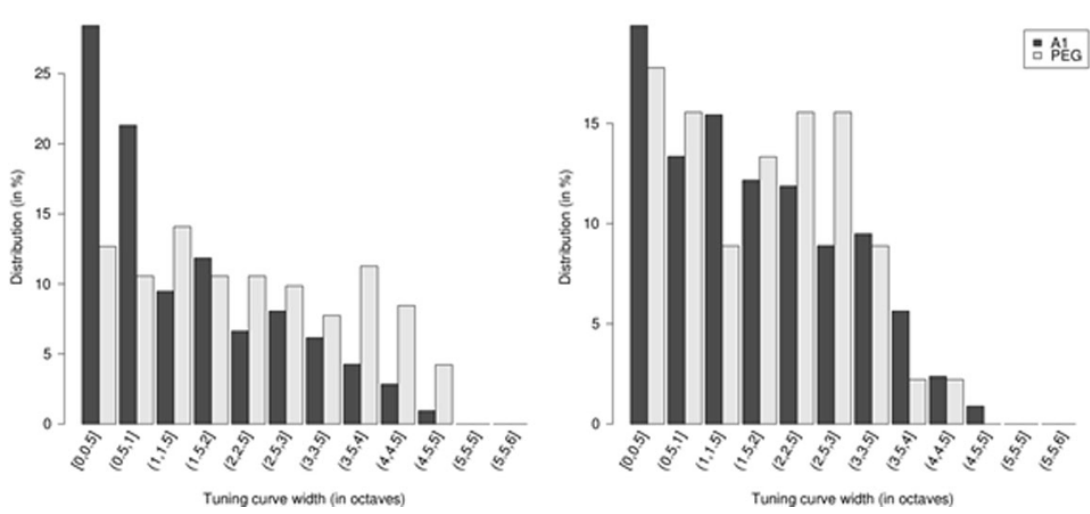

Figure 1 95\% confidence interval in frequency for the highest responses in in A1 and PEG. Left: with pure tones stimuli. Right: with bandpass noise stimuli. The higher values found in PEG compared to A1 demonstrate higher invariance to frequency shifts in PEG than in A1for both stimuli $(p<0.001$, one-sided Mann-Withney $U$ test).

\footnotetext{
* Correspondence: jean.lienard@email.wsu.edu

'Department of Mathematics, Washington State University, Vancouver, WA, USA

Full list of author information is available at the end of the article
} 
in $[2,3]$, indicating as preliminary results that the invariance to time shift is higher in PEG than in A1.

\section{Authors' details}

'Department of Mathematics, Washington State University, Vancouver, WA,

USA. ${ }^{2}$ Oregon Health and Science University, Portland, OR, USA.

Published: 21 July 2014

\section{References}

1. Aldworth ZN, Miller JP, Gedeon T, Cummins Gl, Dimitrov AG: Dejittered spike-conditioned stimulus waveforms yield improved estimates of neuronal feature sensitivity. J Neuro 2005, 25(22):5323-5332.

2. Dimitrov AG, Azouz R, Israeli L: Effects of stimulus transformations on estimated functional properties of mechanosensory neurons. Neurocomputing 2007, 70:1772-1776.

3. Dimitrov AG, Gedeon T: Effects of stimulus transformations on the perceived function of sensory neurons. J Comp Neuro 2006, 20:265-283.

doi:10.1186/1471-2202-15-S1-P170

Cite this article as: Lienard et al:: Characterization of local invariances in the ascending ferret auditory system. BMC Neuroscience 2014 15(Suppl 1): P170.

\section{Submit your next manuscript to BioMed Central} and take full advantage of:

- Convenient online submission

- Thorough peer review

- No space constraints or color figure charges

- Immediate publication on acceptance

- Inclusion in PubMed, CAS, Scopus and Google Scholar

- Research which is freely available for redistribution

Submit your manuscript at www.biomedcentral.com/submit 